\title{
THE SOCIAL SCIENCE OF DATA WAREHOUSING: ITS EVER-EVOLVING CORPORATE CULTURE
}

\author{
Debra J. Borkovich, Robert Morris University, djbst31@mail.rmu.edu
}

\begin{abstract}
Over the past thirty years, the evolution of data warehousing (DW) has provided database management and decision support while concurrently furthering the development of business intelligence and knowledge management strategies through the conduits of people, processes, and technology. This paper offers a literature review of the impact and influence that a fourth and 'softer' perspective, corporate culture, brings to the successful implementation and the growth of a DW. The theories and opinions of subject matter experts and social scientists are reviewed, as well as a nod to the past and a look to the future through the lens of the preeminent data warehousing 'giants of industry', Kimball and Inmon.
\end{abstract}

Keywords: Data Warehousing, Social Science, Corporate (Organizational) Culture, Kimball, Inmon, Big Data Analytics, Textualized ETL, Textual BI, Business Intelligence, Information Systems, Information Technology, Knowledge Management, Workaround

\section{INTRODUCTION}

"The mission of the data warehouse (DW) has always been to collect the data assets of the organization and structure them in a way that is most useful to decision-makers," observes Kimball [34, p. 26]. However, management research has long suggested that to facilitate decision support in the organization, the corporate culture needs to align with the goals and objectives of the DW enterprise and business intelligence (BI) strategy, for without this cultural "glue that welds managers [and employees] together for the implementation of organizational strategies, the absence of this glue would bring about disastrous effects on the organization" [54, p. 305]. Researchers argue that organizational culture is inured and employees tend to embrace information systems that are in concert with their culture and resist those that conflict with their culture [7]. When an organization introduces, modifies, upgrades, or changes its DW architecture, researchers recommend that the culture evolves and progresses likewise in order to ensure economic growth, return on the (technology) investment (ROI), and increase corporate competitiveness. Knowledge management authors often state that for a corporation to be successful and competitive, it must align its most important BI systems' attributes: people, processes, and technology [56, 58, 61] to its corporate culture. Referred to as a "content free expression that can mean different things to different people ... [BI is generally thought of as] an umbrella term that combines architectures, databases [DW], analytical tools, applications and methodologies" [61, p. 8].

Therefore, the purpose of this paper is to explore another attribute and its influential role on DW projects, the corporate culture, often designated as more of a social science or the 'softer side' of BI $[6,23,43]$. This author hypothesizes that corporate culture deserves equal standing with the BI attributes of people, processes, and technology within a solid foundation supporting a successful DW or related IT project.

Through the guise of a literature review, the role of corporate culture will be examined through its influences on people, processes, and technology directly relating to DW/BI. To accomplish this goal, the social science aspects and construct of organizational culture will be described by, examined, and compared to the perspectives of many subject matter experts; including the application of these concepts to corporate leadership, communications, education/training/learning, rewards/incentives, politics and economics, information technology (IT), and decision support. This essay will conclude by looking ahead to predict what the future ever-evolving corporate culture may bring through the thoughtful insights of DW/BI academic and practitioner, Ralph Kimball and the conceptualized theories and research of Bill Inmon. Although this essay represents the current stage of research regarding the influence of corporate culture on DW/BI, first we will briefly explore how it all started through the great 'DW' debate and the evolution of DW 'then and now'. 
Volume XII, No. 1, pp. 23-35, 2011

\section{THE GREAT ‘DW’ DEBATE}

A great deal has transpired since data warehousing made its first appearance in the late 1980s. Known as the "two giants of DW' [2, p. 4), Bill Inmon [29] introduced an IT-centric 'Corporate Information Factory (CIF)' in 1990 and subsequently established Inmon Data Systems, Inmon Consulting, and Forest Rim Technology. As the first to publish and coin the term, 'DW', Inmon [25] became known as the 'Father of DW'; espousing the overall philosophy that supports a 'top-down' developmental approach adapting a traditional normalized relational database to the overarching needs of the enterprise-wide data warehouse (EDW). In 1995, Ralph Kimball [36] re-introduced the concept as a data mart bus architecture with conformed dimensions. Kimball, co-developer of the XEROX Star Workstation and founder of Red Brick Systems and the Kimball Group, supports a user-centric, de-normalized, 'bottom-up' data mart approach espousing the philosophy to "plan big [and] build small . . . which in the case of data warehouses means building one data mart at a time" [61, p. 52].

The popularity of both DW architectures gave rise to years of industry and collegiate debates as to the merits of both systems, comparing the risks and rewards, the drawbacks and benefits. Dependent upon the respective goals, missions, objectives, economies of scale, budgets, and schedules of the organizations implementing DWs, both architectures have maintained their place and usefulness in the industry and each has their fair share of loyal followers. Inmon and Kimball are proven creators and authorities of unique philosophies, methodologies and practices, both of whom have maintained 'legs' in this very fast-paced forward-looking technological society. Over the years, Kimball's bus architecture with conformed dimensions has proven to be the most sensitive and adaptive to user needs, and his DW methodology has provided a more immediate return on investment (ROI) to management due to a faster implementation and a smaller up-front investment of cost and time. The bus architecture's ability to expand as corporate needs dictate, to serve the entire enterprise has been opined by some to be the more popular approach [46, 47]. Conversely, Hwang and Cappel's [24] survey results indicate that long term DW investments in both Inmon's and Kimball's architectures are relatively consistent when spread out over multiple years.

Nevertheless, today's DW architectures are often developed as a hybrid approach of the two philosophies, with major corporate overall DW planning occurring first; and the implementation of individual data marts influenced by the users' priorities and the overall enterprise processes dictating the corporate strategies and implementation [45]. Over the years, the industry successes of the bus [Kimball] and the hub-and-spoke [Inmon] architectures are not all that surprising, as in some ways, "the architectures have evolved over time and become more similar. For example, the hub-and-spoke architecture [Inmon] often includes dimensional data marts [core of the Kimball bus architecture] and each stresses the need to start small and deliver short-term 'wins', but have a long-term plan" [2, p. 6].

This paper does not intend to re-debate the merits of both DW architectures, as this has been done often and well by others [48]. This essay proposes to explore the social science 'softer side' of DW from the perspective of its corporate culture; how it has evolved over the past twenty years; how it has impacted and influenced business intelligence strategies, decision-making, and economics; and then, through the insightful lens of Inmon and Kimball, look ahead to the future corporate culture of DW as it progresses into the next decade.

\section{DATA WAREHOUSING - THEN AND NOW}

In order to explore the evolution of corporate culture during the era of DW, it is necessary to examine its overarching strategic development from the perspectives of the subject matter experts, Inmon and Kimball.

Inmon [27, pp. 48-49] reminds the reader that DW has made great strides since 1983 when,

Someone decided there was a need for information, not data. There arose a need to look across the corporation, not just at a tiny application area.... Thus in 1983 an early form of the data warehousing was born - atomic data. The need for granular integrated historical data opened the doors 
to styles of processing never before possible.

With the data warehouse, business

intelligence became a possibility. Without

the data warehouse, business intelligence

was just a theory.

Inmon [26, p. 66] further argues that successful DW enterprises offer management payoffs that were never before thought possible, such as: lower response time; easy and natural historical analysis; ability to access integrated data; available foundation of reconcilable information; expectation that information comes in waves as the DW project is never really complete; and the realization of lower costs for DW information processing.

Kimball [35] also offers this brief background and a critical forward looking view.

The data warehouse in the late 1980s and early 1990s was regarded as a corporate library of data, definitely something of an archive. In the more than 20 years leading to today, the data warehouse has become increasingly operational, and increasingly tactical. At the same time, IT has been under tremendous pressure to become more business relevant and more business engaged.

All IT organizations have received this message loud and clear. . . . Today the data warehouse is in the midst of a significant increase in pressure from the business world to integrate many more data sources, and to access new forms of data including social media. ... What is exciting is that management can see a very direct causeand-effect between harvesting 'big data' insights, and improvements to the bottom line. [35]

\section{THE SOCIAL SCIENCE EXPERIENCE - THE SOFTER SIDE OF DW}

But how does the influence of corporate culture impact the implementation and success of DW? Breslin [5, p. 19) reports that "having the right set of soft skills is just as important, if not more important, than technical skills and knowledge." Zheng, Yang, and McLean [62, p. 765] add that "Organizational culture does not directly lend its influence on organizational effectiveness; rather it exerts its influence through shaping the behavior of organizational members." Many anthropologists, sociologists, and ethnologists concur and have eloquently defined the construct of culture with respect to organizational management; but for the purposes of this paper, we will begin by examining the cultural concepts of a leading international business management theorist, Geert Hofstede.

For over fifty years Hofstede [23, p. 344] has linked technology to the construct of organizational culture with his classic definition of "the collective programming of the mind which distinguishes the members of one organization from others." Hofstede [21, p. 531] further adds that, "Organizations are not culture free. . . The causality between institutions and culture is circular; they cannot be separated." Hofstede, Hofstede, and Minkov [23] recognize these rites and ceremonies in the business culture as the organizational 'practices' of: symbols, heroes, and rituals; and those ties which bind us within the family, close friends, religious and ethnic groups as: 'values'. Figure 1 captures "The Onion" as a visual depiction of the more superficial corporate 'practices' shown on the outer layers of its skin and the familial 'values' within the onion's core [23, p. 8]. 


\section{Issues in Information Systems}

Volume XII, No. 1, pp. 23-35, 2011

Figure 1

Depiction of "The Onion": Manifestations of Culture at Different Levels of Depth

(Hofstede, Hofstede, \& Minkov, 2010, p. 8)

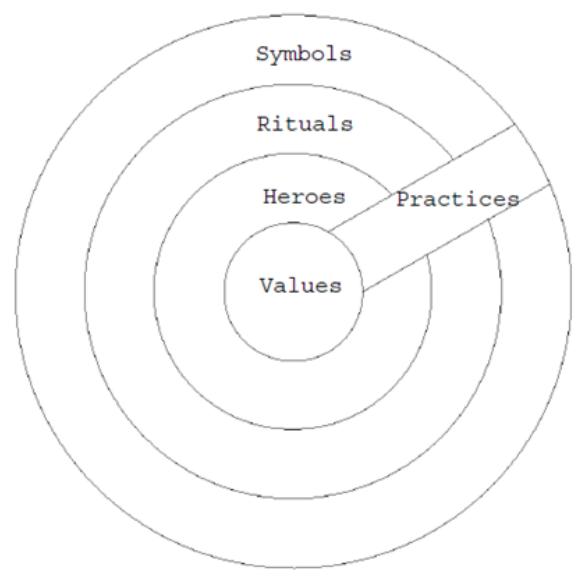

Hofstede's $[18,19,20,21,22]$ prolific writings constantly remind the reader that although 'values' are ingrained and reinforced from birth; 'practices' are learned, inured, and can be changed, such as in the business environment when one moves from one employment situation to another and openly adapts and accepts a new business culture. Two of Hofstede's [17] classic 'terms of art' compare the dimensions of power and control known as 'power distance'; and the management and assessment of risk known as 'uncertainty avoidance', within the social cultural environment of the workplace. These cultural dimensions, emanating from Hofstede's [16, 17] original IBM studies, are benchmark concepts that have withstood the test of time, often quoted in papers and replicated in research studies as secondary analyses. For example, Štok, Markič, Bertoncelj, \& Meško [54, p. 304] offer a similar opinion to further expand the construct of organizational culture with this theory, "Organizational culture is the set of shared philosophies, assumptions, values, expectations, attitudes and norms [artifacts] which bind an organization together."

It is from Hofstede's cultural 'practices' perspective that we continue with the next section to provide a review of insights from researchers who have studied the links between organizational performance and IT-induced cultural changes. These researchers provide specifically pointed advice as to how and why organizational culture influences corporate decision support and decision-making as reflected in its relationships with DW leadership, communications, learning, education, training, rewards, incentives, politics, economics, and technology (i.e. people, processes, and technology).

\section{CORPORATE CULTURE AND LEADERSHIP}

Eckerson [13] argues that DWs succeed not because of the selection of technology, but because of the 'soft' skills of leadership, communication, planning, and interpersonal relationships. Succinctly, Tseng [60, p. 828] notes that organizational culture plays a role in an IT project's success, but without a champion (or team leader) to nurture the desired path, organizational culture can present a major barrier to any worthy program. Equally convinced, Gonzalez [14] avers that "leadership, skill, infrastructure, and value" are essential to achieve DW/BI maturity. Sun [55, p. 517] argues that "Supportive leadership has not only generated empowerment but has also built an innovative culture." Ross [45, p. 666] asserts that information of all types are corporate assets stating, "DW/BI environments aren't immune to cultural or political disorders . . . call in your support group: IT management, business sponsors, and the business community ... [all] must accept its fiduciary responsibility for handling information and analytics as corporate assets. ... The organization will easily see through a veil of verbal commitment if management doesn't exhibit reinforcing behaviors." Others, such as Davenport, Harris, De Long, \& Jacobson [10, p. 136] suggest implementing a data-driven environment with this assertion, "To create data-oriented cultures, senior executives must do more than simply sponsor data-to-knowledge initiatives. They must set strong examples with their own behaviors and insist that others make decisions and take actions based on data." In summary, executive management 
support and the identification of a DW corporate sponsor or DW champion to "define the vision, be an activist, and to communicate a unified message" [56, p. 61] will help pave the way for a consistent and manageable organizational cultural change in concert with IT objectives.

\section{CORPORATE CULTURE AND COMMUNICATIONS}

Becker [3] recommends that the DW/BI team routinely talk to the user community about the ability of the DW environment to meet their needs. "The most important aspect . . is meeting with the business community to solicit their feedback. ... Like organizational therapy we're trying to detect the issues and [find] the opportunities" [3, p. 667]. Becker [3] further adds that interviews and facilitated sessions are the best way to solicit user feedback and to create a face-to-face bond, as surveys are not a reasonable tool to solicit this type of outcome. And Trembly [58, $\mathrm{p}$. 32] observes that, "Data warehouses do great things [but] they also make people nervous. . . One way of encouraging participation is to regularly communicate the status and progress of the data warehousing project to everyone concerned." Sun [55, p. 516] recommends internal 'social networking' to link scarcer knowledge and to broker information flow and needs from different parts of the organization by utilizing the intangible factor of 'social capital'. Doherty and Doig [11, p. 78] "suggest that improvements to the flow of information may have the potential to modify organizational culture, particularly in the area of customer service, flexibility, integration, and empowerment." Others $[9,10]$ recommend that partnering with IT, end-users, and teams from other disciplines helps to solidify a unified message, as well. And with a nod to cognitive psychologist, Simon 49, 50,51,52] who spent a life-time studying human decision-making and its relationship to artificial intelligence, Kimball [34, p. 23] suggests that "good DW also requires an extensive involvement with the business community, and with the cognitive psychology of end-users."

Open communication channels with end-users may include routine face-to-face interviews, focus groups, or unscheduled 'pop-ins' to request decision-support, operational, and usability feedback; however, this author cautions the reader to be conscious of the potential Hawthorne effect, a form of reactivity whereby subjects improve or modify an aspect of their behavior $[56,59]$ simply in response to the fact that they are being observed, interviewed, or questioned and not in response to any particular manipulation or experimentation (in this case, the perceived use of the DW). Routine communications should help to lessen any Hawthorne effects as trust between management, DW analysts, and end-users progresses and grows. Additionally, management and analysts need to allow "an adaptation period during which no observations are made" [53, p. 27] to establish comfort, space, and trust between the users and the DW system before questions are posed.

Early awareness of these potential obstacles, and mandating a two-way street of clear and cogent communications should help to mitigate barriers of mistrust before they become hurdles and detriments to successful DW implementation or modifications to the system. Davenport, Harris, DeLong, and Jacobson [10, p. 125] further add that, "The most sophisticated analyses in the world are worthless if findings cannot be communicated to decisionmakers in ways that will encourage their use".

\section{CORPORATE CULTURE AND EDUCATION/TRAINING/LEARNING}

Thornthwaite [57] asserts that continuous education of management is essential to maintain corporate commitment and to convince the stakeholders of the value and purpose of the DW/BI system. He further adds that "You need to continually gather concrete evidence of success and use that to educate senior management ... the positive result is that as senior management understands the business value of the DW/BI system, they no longer question your budget" [57, p. 673]. Furthermore, "for knowledge creation and decision making, the organization must have a learning culture" [55, p. 517]. Davenport, DeLong, and Beers [8, p. 52] argue that "A culture with a positive orientation to knowledge is one that highly values learning on and off the job and one in which experience, expertise, and rapid innovation supersede hierarchy." In contrast, Doherty and Doig [11, p. 87] remind the reader that "DW projects with wide-ranging change programs, focusing upon working practices, communications, and training. . . . should be recognized that even the realization of such organizational changes may still leave the workforce's 'basic assumptions' at the deepest levels of culture unchanged, at least in the short term." The authors further caution that when implementing DW projects, it is important to "be aware . . . be prepared . . be proactive . . . [and] be realistic" [11, p. 87]. An organization needs to build upon what it already knows because as Davenport, 
Harris, DeLong, and Jacobson [10, p. 125] point out, "You need a deep knowledge of our business processes . . . [because] you can't get the data out of a data warehouse unless you know the business."

\section{CORPORATE CULTURE AND REWARDS/INCENTIVES}

At times it is necessary for management to establish a reward or incentive program for employees to buy-in to the new or modified DW/BI system sooner rather than later. It is not unusual for an employer to motivate and influence the corporate cultural groups with types of employee recognitions such as, bonuses, raises, gift cards, and favorable performance reviews. Lucas [40, p. 419] observes, "Before we adopt new ways of doing things, we establish appropriate rewards for employees who help to implement the changes," and consequently lead the way by utilizing the system. Davenport, DeLong, and Beers [8, p. 54] suggest that "Motivational approaches to encourage more effective behavior should be long-term and should tie in with the general evaluation and compensation structure." Ajmal, Helo, and Kekäle [1, p. 165] add that, "Successful [DW/BI] initiatives require appropriate incentives for team members and a user-friendly information system [that facilitates mutual sharing and trust] thus increasing the likelihood that they will communicate openly and effectively to achieve their shared goals." Tiwana [56, p. 73] observes that, "Employees are not like troops, they are like volunteers. . . . Encouraging use and gaining support requires new reward structures that motivate employees to use the system and contribute to its enthusiastic adoption."

\section{CORPORATE CULTURE, POLITICS, AND ECONOMICS}

Because the creation of a DW can change the way a company does business, "shifts in corporate power may take place" [58, p. 32]. Others warn that a DW/BI project may be "used as an object for political maneuvering such as gaining control and authority" [1, p. 160]". Hammergren and Simon [15, p. 32] observe that "Corporate intrigue and turf wars are the hallmark of business. Business executives and their staff members usually think of information not as a corporate strategic asset, but rather as a personal one."

Marshall [41, p. 12] cautions that politics can play a major role in introducing a DW/BI architecture into the corporate culture with this admonishment, "You can get active resistance to benefits from departmental managers, because one of the consequences of these efficiencies is that their budgets will get reduced next year." In times of a lean economy when staffing and funding are constrained, Becker and Mundy [4, pp. 680-681] recommend "a proactive fitness program that will yield a leaner, more efficient and effective DW/BI program for the long haul." They cite "three key opportunities of: cost savings [identify opportunities to make cuts]; cost avoidance [monitor, defer, and avoid costs]; and growth [quantify the goals, benefits, and the real achievements, such as usage records]" [4, pp. 680-681] as openings to quantify 'good news' to management to encourage the long term viability, stability and growth of the DW/BI system.

Davenport, Harris, DeLong, and Jacobson [10, p. 125] argue that, "Organizational and cultural factors were the greatest barriers to achieving a significant return on their enterprise system investments," advising a required restructuring of analytical resources to support a data-oriented culture as factors essential for success. The authors further comment that trusting the technology to make informed decisions will lead to real business value in a DW/BI data-oriented culture.

Data-based decisions tend to reflect a reality that is often overlooked when decisions are based on experience, intuition, or other such factors alone. In general, data-based decisions tend to reduce bias and unreliable human traits, such as memory. Thus they tend to be more consistent, impersonal, and more cost-efficient to replicate, transfer, and leverage. Data can also be modeled to predict the future, helping mangers make decisions that are timely and responsive 
to their organization's environment.

[10, p. 137]

\section{CORPORATE CULTURE AND INFORMATION TECHNOLOGY}

"Project management skills are the single most important technology resource that comes to play on data warehouse development. Such skills involve management of technology, people, and processes. You must balance all three. Any failure in an area means failure of the project. . . Technology is usually the scapegoat [for project failure], but the technology is proven. It's really about culture change," asserts Trembly [58, p. 41]. For example, employees are creative, innovative and impatient, and if they cannot access an information system, or are frustrated at the rate of response, or just do not know how or what to do, they often implement technical 'workarounds'. Petrides, McClelland, and Modine [42, p. 100] describes 'workarounds' as "informal practices . . . idiosyncratic methods of data collection and management ... both inventive solutions to pressing organizational needs, and over time, costly alternatives to a robust and flexible information system." Akin to this view, Becker [3, p. 18] writes that, "One of the more troubling DW/BI maladies is the business acceptance disorder. In layperson's terms, the business community isn't using the DW/BI environment." Perhaps to avoid or mitigate 'workarounds', Becker [3, p. 18] recommends identifying and diagnosing the symptoms early, soliciting user feedback immediately, embracing their issues and rectifying them, providing additional education or training if warranted, and securing users buy-in. Interestingly, Doherty and Doig [11, p. 87] remark that "It is not the technology, per se, that impacts on culture, but the accompanying changes to working practices and in particular expectations about employees' future behavior. ... Employees will only be truly empowered if they have the motivation, authority, confidence, and the competence to use that information in the decision-making context." Hammergren and Simon [15, p. 32] add that "Data warehousing involves ... the use of technology to break down barriers that are inherent in large companies." Ross [46, p. 208] adds that, "Organizational and cultural obstacles are inevitable as consistent definitions, business rules, and practices are established across the [DW/BI] enterprise. The technology is the easy part."

\section{CORPORATE CULTURE AND DECISION SUPPORT}

"Decisions are not made in a vacuum. They are made in the context of a particular business strategy, a particular set of skills and experience, a particular culture and organizational culture, a particular set of technology, and data capabilities. Most companies tend to focus on just two elements --- technology and data --- or none at all," observes Davenport, Harris, DeLong, and Jacobson [10, pp. 121-122). Figure 2 illustrates their depiction of a knowledge management (KM) strategy: 'from data to knowledge to results'; however, for the purposes of this paper, it clearly shows that the attributes of 'organization and (corporate) culture' have equal standing with 'technology and data' within the foundation and platform supporting an upward path to a successful IT project. 
Volume XII, No. 1, pp. 23-35, 2011

Figure 2

A Model for Building an Analytic Capability (Davenport, Harris, De Long, \& Jacobson, 2001, p. 121)

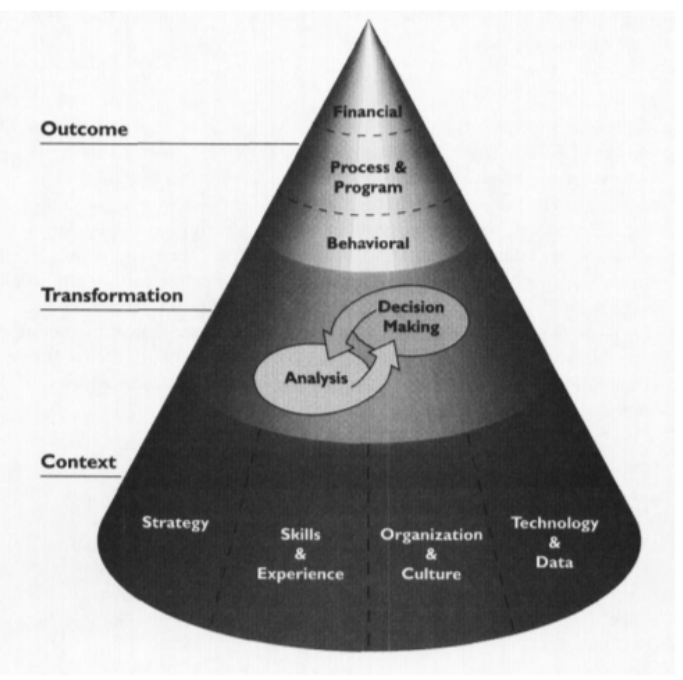

Davenport, DeLong, and Beers [8, p. 50] further recognize that a successful KM project (i.e. DW/BI) is linked to a favorable corporate culture through eight key factors:

- Economic performance or industry value

- Technical and organizational infrastructure

- Standard, flexible knowledge structure

- Knowledge friendly culture

- Clear purpose and language

- Change in motivational practices

- Multiple channels for knowledge transfer

- Senior management support

\section{CORPORATE CULTURE - SUMMARY}

As we have noted through their eloquent and sometimes disparate and diverse verbiage, researchers are generally consistent in their resolve that cultural factors, aligned with corporate objectives and goals, are integral for DW/BI success. Therefore, this author asserts that based upon this specific literature review of subject matter experts, the hypothesis that corporate culture deserves equal standing with the BI attributes of people, processes, and technology supporting a successful DW or related IT project is generally supported. Furthermore, and borrowing from a data analogy, Kelty [32] reminds us that,

Computer programmers are fond of [the

phrase], 'Garbage in, Garbage out' ... a

way of saying ... if one puts in bad data, one will get bad data out.... If the problem

is culture ... then maybe 'Culture in,

Culture out' should be our mantra and

our warning. [32, p. 16] 
Building upon this cache of corporate cultural dynamics and influence upon DW/BI strategies, this paper turns briefly to the future and the projected organizational culture and information systems changes we can look forward to in the next decade, as predicted by the "two giants of DW" [2, p. 4], Ralph Kimball and Bill Inmon.

\section{THE FUTURE OF DW AND ITS CORPORATE CULTURE}

Recently this author had the unique experience to read an advance copy of Kimball's [34] latest White Paper and the opportunity to ask him to opine about the future of DW. Sharing his keen insights and observations for the future of corporate culture, and in true Kuhnian [39] 'normal science' fashion, Kimball [34] predicts that a new DW paradigm ['shift'] and "something between a midcourse correction and a revolution for enterprise data warehousing" will surface supporting the importance of 'big data' analytics. Kimball [34, p. 1] defines 'big data' as "structured, semistructured, unstructured, and raw data in many formats [i.e., petabytes of behavioral and image data; and social media], in some cases looking totally different that the clean scalar numbers and text we have stored in our data warehouses for the last 30 years. The 'big data' revolution is about finding new value within and outside conventional data sources." Kimball [34, p. 22] advocates that, "New skill sets, new organizations, new development paradigms, and new technology will need to be absorbed by many enterprises. . . This kind of tinkering and adjusting to new paradigms is normal and expected. We went through a very similar phase in the early 1990s when data warehousing itself was a new paradigm for IT and the business." Kimball [34, p. 18] asserts that, "The enterprise data warehouse [EDW] must absolutely stay relevant to the business. As the value and the visibility of 'big data' analytics grows, the data warehouse must encompass the new culture, skills, techniques, and systems required for 'big data' analytics." Kimball [34] further projects that the information landscape is subject to change through the recruitment of more skilled technical analysts with deep expertise evidencing a culture shift toward creativity and innovation to meet the needs of rapid short-term experimentation projects aimed at solving the future goals of 'big data' issues. Kimball [34, p. 1] challenges information management professionals to "progress from a remarkably stable EDW architecture to the new era of 'big data' analytics." For further insight and a particularly compelling argument regarding the future of DW, 'big data', and the impact, integration, and deployment of social media, readers are encouraged to access Kimball's [34] White Paper entitled, "The Evolving Role of the Enterprise Data Warehouse in the Era of Big Data Analytics" accessible at www.informatics.com.

Equally insightful and intriguing was the unique opportunity to secure a one-on-one conversation with the 'Father of Data Warehousing (DW)', Bill Inmon. Of primary interest was Inmon's opinion of the future of DW and where it may venture within the next decade. Inmon [31] projects that the "Unstructured DW within the next ten to twentyfive years will be primarily comprised of 'textual information', such as contractual, medical, legal, patents, memos, and email data, to accompany the standardized transactional data." In his White Paper entitled, "Managing Text in Corporate Contracts," Inmon [28, p. 8] lays the foundation for capturing contractual text in a database or DW that far exceeds the traditional key word indexing within a "specialized textual process [known] generically as textualized ETL [extract, transform, load]," currently patent pending. Furthermore, Inmon's [30, p. 3] White Paper, "Textual Business Intelligence," describes the salient differences between the classical data warehouse comprised of "numeric . . repetitive ... [and] other supporting data - points of interest - surround[ing] and attached to the numeric data"; and his prediction that the primary contents of the future unstructured DW will be text which will not work well in the classic DW and business intelligence (BI) environment. Inmon describes this next generation DW situation, known as DW2.0 ${ }^{\mathrm{TM}}$, as requiring "an entirely different kind of BI. What is needed is Textual BI" [30, p. 6]. Inmon [31] argues that in some cases the current BI of any organization can be approximated as high as $80 \%$ of text-based documentation, at times resulting in a mere $20 \%$ of BI manifested in numeric, repetitive transactional data captured in a DW. However, Inmon [30, p. 13] aptly reassures the reader by concluding this White Paper with the reminder that Textual BI will not be a replacement for classical BI with the statements, "Textual BI and classical BI are complementary. A sophisticated organization is going need BOTH forms of business intelligence." In concert with his predictions and with a nod to the ever-changing corporate culture, Inmon remarks that not only new types of innovative and creative data programmers and analysts will be required, but that organizational end-users and decision-makers will also have to be open-minded forward-thinkers to embrace the dynamic changes that await all of us in the not so distant DW/BI future [31]. For detailed information about the pending impact of 'Textualized ETL' and 'Textual BI' on corporate documentation, readers are encouraged to access Inmon's White Papers at www.inmoncif.com. 


\section{CONCLUSION}

Research points to management and employees alike, to embrace the DW/BI corporate cultural changes of the future and to continue building upon what has already been learned and implemented to support Kimball's potential 'new paradigm', or if need be, merely to stay abreast of the future growth and capacity of the petabyte generation. The natural human struggle to resist change is at odds with the natural technological impulse of IS/IT professionals, innovators and early adopters [44] to embrace change, at times placing both cultural philosophies on opposite ends of the spectrum. Continued application of appropriate communications, leadership skills, interpersonal relationships, trust, motivation, incentives, learning, technology stimulation, corporate 'practices', and familial 'values' as part of an organizational culture will positively affect business excellence in enterprises [54, p. 311]. Donate and Guadamillas [12, p. 92] remind the reader that corporate commitment to the development and nurturing of a "culture that promotes and encourages these practices toward organizational objectives will be essential to achieving competitive advantages based on technological innovation."

Kimball [34] pragmatically and optimistically sums up the future technological culture of DW with this statement.

Sometimes when an exciting new

technology arrives, there is a tendency to

close the door on older technologies as if

they were going to go away. DW has

built an enormous legacy of experience,

best practices, supporting structures,

technical expertise, and credibility with

the business world. This will be the

foundation for information management

in the upcoming decade as DW expands

to include 'big data' analytics. [34, p. 27]

This researcher might hazard a guess or even boldly surmise that both Inmon and Kimball are philosophers and innovators of a parallel vein, merely following a different theory, each on his own unique path of inquiry. One might even imagine that the final line of Kimball's quote could be emended to read 'textualized', in lieu of 'big data', to portray Inmon's concept because they are both so focused on the future success of DW/BI. Multiple perspectives are needed to provide balance to any topic; therefore it is gratifying to know that both 'DW giants' continue to research, develop, think, plan, practice and teach; and this author has been privileged to learn from both.

Therefore, based upon this collection (albeit limited) of opinions and theories posed by technical subject matter experts, cultural theorists, and social scientists, this author believes that corporate culture has a great deal more influence and impact on business intelligence and decision support systems than traditionally considered. Therefore, placing the social science of corporate culture on an equal footing with people (users), processes (decision-support systems, BI, KM), and technology (DW), may prove to be a prudent business practice to ensure the longevity, stability and continued development of its ever-evolving database management system, the DW. Further review and study of DW's challenging social science 'softer side' may just uncover additional corporate cultural attributes worthy of a second look.

\section{ACKNOWLEDGEMENT}

The author would like to thank Dr. Ralph Kimball (www.kimballgroup.com) and Julie Kimball for pre-publication access to his latest White Paper, and for providing copies of The Kimball Reader [38], Data Warehousing Toolkits $[36,37]$, and other resources to aid in this research. Thanks are also extended to Bill Inmon (www.inmoncif.com) who generously shared his experiences, insights, knowledge, and time with this researcher. These individuals truly represent the epitome of scholarly cooperation, knowledge sharing, leadership, and trust that every corporate culture should strive to achieve. 


\section{REFERENCES}

1. Ajmal, M., Helo, P., \& Kekäle, T. (2009). Critical factors for knowledge management in project business. Journal of Knowledge Management, 14(1), 156-168.

2. Ariyachandra, T., \& Watson, H. J. (2006). Which data warehouse architecture is most successful? Business Intelligence Journal, 11(1), 4-6.

3. Becker, B. (2004). Boosting business acceptance. In R. Kimball, \& M. Ross (Eds.), The Kimball Book Reader (pp. 667-670). Indianapolis, IN: Wiley Publishing, Inc.

4. Becker, B., \& Mundy, J. (2009). Data warehousing fitness program for lean times. In R. Kimball, \& M. Ross (Eds.), The Kimball Book Reader (pp. 680-684). Indianapolis, IN: Wiley Publishing.

5. Breslin, M. (2004). Data warehousing battle of the giants: Comparing the basics of the Kimball and Inmon models. Business Intelligence Journal, 9(1), 6-20.

6. Cassell, J. (2002). Perturbing the system: "Hard science," "soft science," and social science, the anxiety and madness of method. Human Organization, 61(2), 177-185.

7. Cooper, R. B. (1994). The inertial impact of culture on IT implementation. Information Management, 27, 17-31.

8. Davenport, T. H., De Long, D. W., \& Beers, M. C. (1998). Successful knowledge management projects. Sloan Management Review, 39(2), 43-57.

9. Davenport, T. H., \& Vögel, S. C. (2001). The rise of knowledge toward attention management. Journal of Knowledge Management, 5(3), 212-221.

10. Davenport, T. H., Harris, J. G., De Long, D. W., \& Jacobson, A. L. (2001). Data to knowledge to results: Building an analytic capability. California Management Review, 43(2), 117-138.

11. Doherty, N. F., \& Doig, G. (2003). An analysis of the anticipated cultural impacts of the implementation of data warehouses. IEEE Transactions on Engineering Management, 50(1), 78-88.

12. Donate, M. J., \& Guadamillas, F. (2010). The effect of organizational culture on knowledge management practices and innovation. Knowledge and Process Management, 17(2), 82-94.

13. Eckerson, W. (2003). Smart companies in the $21^{\text {st }}$ century: The secrets of creating business intelligence solutions. TDWI Website. Retrieved August 11, 2003, from http://www.dw-institute.com/research/

14. Gonzales, M. (2011). Success factors for business intelligence and data warehousing maturity and competitive advantage. Business Intelligence Journal, 16(1), 22-29.

15. Hammergren, T. C., \& Simon, A. R. (2009). Data warehousing for dummies ( $2^{\text {nd }}$ ed.). Hoboken, NJ: Wiley Publishing, Inc.

16. Hofstede, G. (1968). The game of budget control. London: Tavistock Publications Limited. [Reprinted in 2001. London: Routledge].

17. Hofstede, G. (1983). National cultures in four dimensions: A research-based theory of cultural differences among nations. International Studies of Management and Organizations, 13(1-2), 46-74.

18. Hofstede, G. (1990). Measuring organizational cultures: A qualitative and quantitative study across twenty cases. Administrative Science Quarterly, 35(2), 286-316.

19. Hofstede, G. (1993). Cultural constraints in management theories. The Executive, 7(1), 81-94.

20. Hofstede, G. (1994). Business cultures. The Unesco Courier, 4, 12-14. Retrieved June 29, 2010, from Research Library. (Document ID: 8733488).

21. Hofstede, G. (1996). An American in Paris: The influence of nationality on organization theories. Organization Studies, 17(3), 525-537.

22. Hofstede, G. (1998). Attitudes, values and organizational culture: Disentangling the concepts. Organizational Studies, 19(3), 477- 492.

23. Hofstede, G., Hofstede, G. J., \& Minkov, M. (2010). Cultures and organizations: software of the mind. New York, NY: McGraw-Hill.

24. Hwang, M., \& Cappel, J. J. (2002). Data warehouse development and management: Practices of some large companies. The Journal of Computer Information Systems, 43(1), 3-6.

25. Inmon, W. H. (2002). Building the data warehouse ( $3^{\text {rd }}$ ed.). New York, NY: John Wiley \& Sons. (Original work published 1990)

26. Inmon, W. H. (2004). Measuring success. DM Review, 14(9), 66.

27. Inmon, W. H. (2005). A brief history of architecture. DM Review, 15(4), 48-50. 
Volume XII, No. 1, pp. 23-35, 2011

28. Inmon, W. H. (2008). Managing text in corporate contracts. [White Paper] pp. 1-12. Retrieved from http://inmoncif.com.registration/whitepapers/index.php

29. Inmon, W. H. (2010). A tale of two architectures. [White Paper] pp. 1-15. Retrieved from http://inmoncif.com.registration.whitepapers/index.php

30. Inmon, W. H. (2011). Textual business intelligence. [White Paper] pp. 1-13. Retrieved from http://inmoncif.com.registration.whitepapers/index.php

31. Inmon, W. H., personal communication, May 10, 2011.

32. Kelty, C. (2010). Anthropological perspectives on knowledge in the digital age - Introduction: Culture in, culture out. Anthropological Quarterly, 83(1), 7-16.

33. Kimball, R. (1995). The database market splits. In R. Kimball, \& M. Ross (Eds.), The Kimball Book Reader (pp. 36-38). Indianapolis, IN: Wiley Publishing, Inc.

34. Kimball, R. (2011). The evolving role of the enterprise data warehouse in the era of big data analytics. [White Paper] pp. 1-28. Retrieved from http://www.informatica.com/downloads/1597_EDW_Big_Data_Analytics_Kimball.pdf

35. Kimball, R., personal communication, March 14, 2011.

36. Kimball, R., \& Ross, M. (2002). The data warehouse toolkit: The complete guide to dimensional modeling ( $2^{\text {nd }}$ ed.). New York, NY: John Wiley \& Sons. (Original work published 1996)

37. Kimball, R., Ross, M., Thornthwaite, W., Mundy, J., \& Becker, B. (2008). The data warehouse lifecycle toolkit $\left(2^{\text {nd }}\right.$ ed.). New York, NY: John Wiley \& Sons. (Original work published 1998)

38. Kimball, R., \& Ross, M. (2010). The Kimball Group reader. Indianapolis, IN: Wiley Publishing.

39. Kuhn, T. (1996). The structure of scientific revolutions ( $3^{\text {rd }}$ ed.). Chicago: The University of Chicago Press. (Original work published 1970)

40. Lucas, L. M. (2010). The role of teams, culture, and capacity in the transfer of organizational practices. The Learning Organization, 17(5), 419-436.

41. Marshall, M. (1997). Beware of office politics --- Technology improvements are not always popular, data warehousing managers learn. Communications Week, June 2(666), 12.

42. Petrides, L., McClelland, S., \& Nodine, T. (2004). Costs and benefits of the workaround: Inventive solution or costly alternative. The International Journal of Educational Management, 18(2/3), 100-108.

43. In praise of soft science. (2005). Nature, 435(7045), 1003.

44. Rogers, E. M. (2003). Diffusion of Innovations ( $5^{\text {th }}$ ed.). New York, NY: Free Press, a Division of Simon \& Schuster Inc. (Original work published 1962)

45. Ross, M. (2004). Data warehouse checkups. In R. Kimball, \& M. Ross (Eds.), The Kimball Book Reader (pp. 661-667). Indianapolis, IN: Wiley Publishing.

46. Ross, M. (2004). Fables and facts. In R. Kimball, \& M. Ross (Eds.), The Kimball Book Reader (pp. 204-208). Indianapolis, IN: Wiley Publishing.

47. Ross, M., \& Kimball, R. (2003). The bottom-up misnomer. Intelligent Enterprise, 6(15), 24-27.

48. Sherman, R. (2005). Hub-and-Spoke Redux. DM Review, 15(5), 60.

49. Simon, H. (1987a). Decision making and problem solving. INTERFACES, 17(5), 11-31.

50. Simon, H. (1987b). Making management decisions: The role of intuition and emotion. Academy of Management Executive, 1(1), 57-64.

51. Simon, H. (1993). Decision making: rational, nonrational, and irrational. Educational Administration Quarterly, 29(3), 392-411.

52. Simon, H. (1997). Administrative behavior: A study of decision-making processes in administrative organizations $\left(4^{\text {th }}\right.$ ed.). New York: THE FREE PRESS. (Original work published 1945)

53. Spector, P. E. (1981). Research designs. Newbury Park, CA: SAGE Publications, Inc.

54. Štok, Z. M., Markič, M., Bertoncelj, A., \& Meško, M. (2010). Elements of organizational culture leading to business excellence. Zb. rad. Ekon. fak. Rij., 28(2), 303-318.

55. Sun, P. (2010). Five critical knowledge management organizational themes. Journal of Knowledge Management, 14(4), 507-523.

56. Tiwana, A. (2002). The knowledge management toolkit: Orchestrating IT, strategy, and knowledge platforms $\left(2^{\text {nd }}\right.$ ed.). Upper Saddle River, NJ: Prentice Hall.

57. Thornthwaite, W. (2007). Educate management to sustain DW/BI success. In R. Kimball, \& M. Ross (Eds.), The Kimball Book Reader (pp. 670-673). Indianapolis, IN: Wiley Publishing. 
58. Trembly, A. C. (2001). Experts: Technology is not to blame for data warehouse failures. National Underwriter, 105(45), 32-41.

59. Trochim, W., \& Donnelly, J. (2008). The research methods knowledge base (3 ${ }^{\text {rd }}$ ed.). Mason, OH: Atomic Dog, a part of CENGAGE Learning.

60. Tseng, S-M. (2010). The effects of hierarchical culture on knowledge management processes. Management Research Review, 33(8), 827-839.

61. Turban, E., Sharda, R., Delen, D., \& King, D. (2011). Business intelligence: A managerial approach (2 ${ }^{\text {nd }}$ ed.). Upper Saddle River, NJ: Prentice Hall.

62. Zheng, W., Yang, B., \& McLean, G. N. (2010). Linking organizational culture, structure, strategy, and organizational effectiveness: Mediating role of knowledge management. Journal of Business Research, 63, 763-771. 